JURNAL ANALIS KESEHATAN
KLINIKAL SAINS
UNIVERSITAS
http://jurnal.univrab.ac.id/index.php/klinikal

\title{
IDENTIFIKASI JAMUR Aspergillus sp PADA ROTI TAWAR SEBELUM MASA KADALUARSA DI PASAR BURUNGTUNGKU KOTA BANDUN
}

\author{
Ni’matul Murtafi’ah, Nurhani Sapitri, Arie J. Pitono \\ Institut Kesehatan Rajawali (DIV Teknologi Laboratorium Medik, Fakultas Kesehatan) \\ Alamat : Jalan Rajawali Barat Nomor 38 Bandung 40184 \\ Telp (022) 6079141 \\ Alamat e-mail: nimatul.murtafiah@yahoo.co.id \\ No. Hp coresponding author $(087825783973)$
}

\section{Info Artikel}

Sejarah Artikel:

Diterima November 2021

Disetujui Desember 2021

Dipublikasikan Desember

2021

Keywords:

Keyword; Keyword; Keyword

\section{Abstrak}

Roti tawar adalah salah satu makanan yang berbahan dasar tepung terigu di fermentasikan dengan ragi (Saccharomyces cerevisiae) dan penambahan bahan lainnya. Jamur merupakan mikroorganisme utama berperan penting dalam proses pembuatan dan pembusukan roti. Jamur Aspergillus sp merupakan jamur kontaminan umum pada berbagai substrat salah satunya pada roti tawar. Tujuan penelitian ini adalah untuk mengidentifikasi jamur Aspergillus sp pada roti tawar sebelum masa kadaluarsa di Pasar Minggu Burung Tungku Kota Bandung. Penelitian dilakukan dengan menggunakan metode deskriptif yaitu dengan isolasi jamur pada media SDA (Sabaroud Dextrose Agar) kemudian disimpan selama 5 hari di inkubator pada suhu $27^{\circ} \mathrm{C}$, setelah itu di periksa di bawah mikroskop dengan penambahan larutan LPCB (Lactophenol Cotton Blue). Berdasarkan hasil pengamatan dari 4 jenis roti tawar 3 jenis roti tawar 2 hari sebelum masa kadaluarsa hasilnya positif di temukan jamur kontaminan pada sampel roti tawar 1 , 3, dan roti tawar 4. Pada sampel roti tawar 1 dan 3 ditemukan jamur kontaminan Aspergillus fumigatus dan pada sampel roti tawar 4 ditemukan jamur kontaminan Aspergillus flavus. Dari hasil penelitian di atas dapat disimpulkan bahwa roti tawar 2 hari sebelum masa kadaluarsa terkontaminasi oleh jamur golongan Ascomycetes yaitu Aspergillus sp.

Kata Kunci: Roti Tawar, Aspergillus sp, Aspergillus flavus, Aspergillus fumigatus.

\section{Abstract}

Bread is a food made from wheat flour fermented with yeast (Saccharomyces cerevisiae) and the addition of other ingredients. Fungi are the main microorganisms that play an important role in the process of making and spoiling bread. Aspergillus sp is a common contaminant fungus on various substrates, one of which is white bread The purpose of this study was to identify the fungus Aspergillus sp in white bread before the expiration date at the Pasar Minggu Burung Tungku, Bandung City.The study was conducted using a 
descriptive method, namely by isolating the fungus on SDA media (Sabaroud Dextrose Agar) then stored for 5 days in an incubator at $27^{\circ} C$, after that it was examined under a microscope with the addition of LPCB (Lactophenol Cotton Blue) solution.Based on observations from 4 types of white bread, 3 types of white bread 2 days before the expiration date, the positive results were found to be contaminant fungi in samples of white bread 1, 3, and white bread 4. In samples of white bread 1 and 3 found contaminant fungi Aspergillus fumigatus and in sample of white bread 4 found contaminant fungi Aspergillus flavus. From the results of the research above, it can be concluded that the white bread 2 days before the expiration date was contaminated by Ascomycetes fungi, namely Aspergillus sp.

Keywords: Bread, Aspergillus sp, Aspergillus flavus, Aspergillus fumigatus.

(C) 2021

Universitas Abdurrab

Alamat korespondensi:

Institut Kesehatan Rajawali (DIV Teknologi Laboratorium

Medik, Fakultas Kesehatan) Alamat : Jalan Rajawali Barat

Nomor 38 Bandung 40184

nimatul.murtafiah@yahoo.co.id

\section{PENDAHULUAN}

Menurut UU RI NO. 18 Tahun 2012 pangan merupakan segala sesuatu berasal dari sumber hayati seperti dari hasil pertanian, perkebunan, perhutanan, perikanan, peternakan dan perairan, baik yang diolah maupun tidak diolah sebagai makanan atau minuman yang dikonsumsi oleh manusia. Kebutuhan pangan bagi kelangsungan hidup manusia sangat penting. Salah satu contoh pangan yang sering dikonsumsi oleh masyarakat sebagai sarapan adalah roti (Prasetyarini et al., 2014).

Roti adalah salah satu makanan berbahan dasar tepung terigu di fermentasikan dengan ragi (Saccharomyces cerevisiae) dan penambahan bahan lainnya. Roti termasuk makanan pengganti nasi karena mengandung nilai gizi baik, kandungan kabohidrat tinggi, serata rasanya lezat, sehingga roti sering digunakan sebagai makanan pengganti nasi (Pusuma et al, 2018). Roti termasuk kedalam makanan mudah rusak dengan masa simpan 3-4 hari. Rusaknya protein dan pati menyebabkan perubahan pada roti, secara langsung perubahan roti disebabkan oleh kontaminan jamur. Jamur sering di temukan dalam roti adalah Rhizopus stolonifer, Penicillium Expansum, Aspergillus sp, Aspergillus niger dan Aspergillus flavus (Sulastina, 2020).

Aspergillus adalah salah satu mikroorganisme eukariot mempunyai daerah penyebaran paling luas dan berlimpah di alam, pada berbagai substrat di daerah tropis dan subtropis jenis jamur ini merupakan jamur kontaminan paling umum. Oleh sebab itu, kemungkinan besar banyak jenis Aspergillus dapat hidup pada roti tawar. Aspergillus diketahui mempunyai enzim dapat memfasilitasi aktivitas biodegradatif Aspergillus. Mampu memfermentasi makanan dan 
proses industri lainnya, seperti industri minuman, konversi biomasa, pengolahan limbah dan produksi bahan kimia. Jamur Aspergillus $s p$ menghasilkan beberapa mikotoksin atau sering di kenal dengan alfatoksin. Aflatoksin paling sering mengkontaminasi bahan makanan dan menyebabkan penyakit bagi manusia, memiliki sifat karsinogenik dan hepatotoksik (Mizana et $a l, .2016)$.

Damapak kesehatan yang ditimbulkan oleh Aspergillus sp adalah demam, peradangan, sesak nafas, nyeri dada, nyeri sendi, batuk-batuk, mengigil, sakit kepala, kanker hati dan aspergillosis. Kontaminasi jamur mengakibatkan kerusakan dan penyimpanan pada makanan. Jamur tumbuh lebih cepat di lingkungan yang memiliki kelembaban tinggi atau basah (Hasanah, 2017).

Berdasarkan fenomena di lapangan ketika saya membeli roti tawar di pasar minggu burung tungku, di temukan bintik bintik seperti jamur pada roti tawar tersebut padahal masa kadaluarsanya masih lama. oleh sebab itu saya mencurigai bahwa kemungkinan terdapat jamur kontaminan pada roti tersebut. Menurut penelitian Syaifuddin (2017) Jamur Aspergillus sp pada roti tawar berdasarkan masa sebelum dan sesudah kadaluwarsa di Candimulyo Jombang dari 4 sampel yang diteliti ternyata di temukan 3 jenis jamur Aspergillus pada setiap sampel roti tersebut yaitu A.flavus, A.niger, dan A.fumigatus.

\section{METODE}

Penelitian dilaksanakan dengan menggunakan teknik isolasi menggunakan media SDA (Sabouraud Dextrose Agar) dan pengamatan secara makroskopik dan mikroskopik. Sampel yang diambil dalam penelitian ini yaitu 4 jenis roti tawar 2 hari sebelum masa kadaluarsa di Pasar Burungtungku Kota Bandung, bagian sampel yang digunakan yaitu bagain atas roti, bagain tengah roti dan bagian bawah roti. Penelitian ini dilaksanakan pada bulan JuniSeptember 2021, bertempat di Laboratorium Bakteriologi Institut Kesaehatan Rajawali.

Alat dan bahan yang digunakan dalam penelitian ini yaitu:Autoklaf, Akuades steril, Batang pengaduk, beaker glass, cawan petri, gelas ukur, erlemeyer, laminar air flow, inkubator, mikroskop, plastik warp, lampu spirtus, tabung reaksi, ose jarum, alumunium foil, alkohol 70\%, media SDA, reagen LPCB, roti tawar, tisue, kapas, korek api, plastik, kertas sampul. Data yang didapat merupakan data primer yang diperoleh dari hasil pengamatan secara makroskopik dan mikroskopik. Data hasil penelitian yang didapatkan dianalisis dan disimpulkan.

\section{Prosedur Kerja}

Pembutan Media SDA (Sabouraud Dextrose Agar) (Amalia, 2013).

Menimbang media SDA (Sabouraud Dextrose Agar) sebanyak 12,8 gram. Melarutkan dengan $195 \mathrm{ml}$ akuades steril. Mehomogenkan dengan cara mengaduk. Mepanaskan di atas 
Ni'matul Murtafi'ah, Nurhani Sapitri, Arie J. Pitono / Jurnal Analis Kesehatan Klinikal Sains 9 (2) (2021) lampu spirtus dan di aduk sampai mendidih. Menuangkan ke dalam labu Erlemeyer dan tutup mulut labu Erlemyer dengan kapas sumbat dan alumunium foil. Mensterilkan media dengan menggunakan autoklaf pada suhu $121^{\circ} \mathrm{C}$ selama 15 menit. Medinginkan selama 2 menit dan tuangkan ke dalam cawan petri.

Isolasi Roti Tawar pada Media SDA (Sabouraud Dextrose Agar) (Amalia, 2013).

Mengambil sedikit roti tawar kira-kira 1 gram dan letakkan di atas media SDA (Sabouraud Dextrose Agar) yang sudah di masukan ke cawan petri. Mefiksasi cawan petri yang sudah di tanami roti tawar setelah itu diinkubasi selama 5 hari pada suhu $27^{\circ} \mathrm{C}$. Mengamati pertumbuhan koloni pada media secara makroskopis dengan melihat warna koloni, warna atas, warna pinggiran, radial furrow, exudate drop, pada media.

\section{Pewarnaan Jamur}

Lactophenol Cotton Blue diteteskan diatas kaca objek glass. Koloni jamur diambil dengan jarum ose secara aseptis kemudian koloni direnggangkan dan tutup dengan cover glass.

\section{Pengamatan Mikroskop}

Koloni jamur yang sudah di cat dengan Lactopenol Cotton Blue, kemudian dibaca dibawah mikroskop dari perbesaran lemah sampai perbesaran kuat 10x10 sampai 40x10. Kemudian amati ada tidaknya jamur Aspergillus sp, warna jamur, bentuk jamur, konidia, vesicle, dan hifa bersepta atau tidak.

\section{HASIL DAN PEMBAHASAN}

Isolasi sampel roti tawar pada media SDA diinkubasi selama 5 hari di inkubator pada suhu $27{ }^{\circ} \mathrm{C}$, setelah itu dilakukan pengamatan secara makroskopik dengan melihat ada atau tidaknya jamur Aspergillus sp pada sampel. Hasil pengamatan secara makroskopik dapat dilihat pada Tabel 1.

Tabel 1. Hasil Pengamatan Secara Makroskopik

\begin{tabular}{cccccccc}
\hline No & $\begin{array}{c}\text { Kode } \\
\text { Sampel }\end{array}$ & $\begin{array}{c}\text { Bagian } \\
\text { Sampel }\end{array}$ & $\begin{array}{c}\text { Warna } \\
\text { Koloni }\end{array}$ & $\begin{array}{c}\text { Radial } \\
\text { Furrow }\end{array}$ & $\begin{array}{c}\text { Exudat } \\
\text { Drop }\end{array}$ & $\begin{array}{c}\text { Warna } \\
\text { Atas }\end{array}$ & $\begin{array}{c}\text { Warna } \\
\text { pinggiran }\end{array}$ \\
\hline 1. & RT 1 & Atas & $\begin{array}{c}\text { Hijau } \\
\text { kelabu }\end{array}$ & - & - & Hijau & Putih \\
\hline & & Tengan & - & - & - & - & - \\
\hline & & Bawah & - & - & - & - & - \\
\hline No & $\begin{array}{c}\text { Kode } \\
\text { Sampel }\end{array}$ & $\begin{array}{c}\text { Bagian } \\
\text { Sampel }\end{array}$ & $\begin{array}{c}\text { Warna } \\
\text { Koloni }\end{array}$ & $\begin{array}{c}\text { Radial } \\
\text { Furrow }\end{array}$ & $\begin{array}{c}\text { Exudat } \\
\text { Drop }\end{array}$ & $\begin{array}{c}\text { Warna } \\
\text { Atas }\end{array}$ & $\begin{array}{c}\text { Warna } \\
\text { pinggiran }\end{array}$ \\
\hline
\end{tabular}


Ni’matul Murtafi'ah, Nurhani Sapitri, Arie J. Pitono / Jurnal Analis Kesehatan Klinikal Sains 9 (2) (2021)

\begin{tabular}{cccccccc}
\hline 2. & RT 2 & Atas & - & - & - & - & - \\
\hline & & Tengan & - & - & - & - & - \\
\hline & & Bawah & - & - & - & - & - \\
\hline 3. & RT 3 & Atas & Hijau tua & - & - & Hijau & Hijau \\
\hline & & Tengan & - & - & - & - & - \\
\hline & & Bawah & Hijau tua & - & - & Hijau & Hijau \\
\hline 4. & RT 4 & Atas & - & - & - & - & - \\
\hline & & Tengan & - & - & - & - & - \\
\hline & & Bawah & $\begin{array}{c}\text { Hijau } \\
\text { kekuningan }\end{array}$ & Ada & Ada & Hijau & Kuning \\
& & & & & & \\
\hline
\end{tabular}

Berdasarkan Tabel 1 diperoleh hasil pengamatan secara makroskopik pada 4 jenis sampel roti tawar 3 jenis roti tawar hasilnya positif ditumbuhi jamur kontaminan dengan melihat ciri-ciri makroskopik jamur. Adapun hasilpengamatan mikroskopik yang di perolehdapat di lihat pada Tabel 2.

Tabel 2. Hasil Pengamatan Secara Mikroskopik

\begin{tabular}{cccccccc}
\hline No & $\begin{array}{c}\text { Kode } \\
\text { Sampel }\end{array}$ & $\begin{array}{c}\text { Bagian } \\
\text { Sampel }\end{array}$ & $\begin{array}{c}\text { Warna } \\
\text { Jamur }\end{array}$ & $\begin{array}{c}\text { Bentuk } \\
\text { Jamur }\end{array}$ & Konidia & Vesicle & $\begin{array}{c}\text { Hifa } \\
\text { Bersepta }\end{array}$ \\
\hline 1. & RT 1 & Atas & Biru & Bulat & Ada & Ada & $\begin{array}{c}\text { Tdk } \\
\text { bersepta }\end{array}$ \\
\hline & & Tengan & - & - & - & - & - \\
\hline 2. & RT 2 & Atas & - & - & - & - & - \\
\hline & & Tengan & - & - & - & - & - \\
\hline & & Bawah & - & - & - & - & - \\
\hline 3. & RT 3 & Atas & Biru & Kipas & Ada & Ada & $\begin{array}{c}\text { Tdk } \\
\text { bersepta }\end{array}$ \\
\hline & & Tengan & - & - & - & - & - \\
\hline & & Bawah & Biru & Kipas & Ada & Ada & $\begin{array}{c}\text { Tdk } \\
\text { bersepta }\end{array}$ \\
\hline 4. & RT 4 & Atas & - & - & - & - & - \\
\hline & & Tengan & - & - & - & - & - \\
\hline & & Bawah & Biru & Bulat & Ada & Ada & $\begin{array}{c}\text { Tdk } \\
\text { Bersepta }\end{array}$ \\
\hline
\end{tabular}

Berdasarkan tabel 2 diperoleh hasil pengamatan secara mikroskopik dari 3 jenis sampel roti tawar yang positif ditemukannya jamur kontaminan dengan ciri mikroskopik sesuai dengan karakteristik dan ciri jamur Aspergillus sp dapat di lihat pada Tabel 3.

Tabel 3. Hasil Pemeriksaan Jamur 
Ni’matul Murtafi'ah, Nurhani Sapitri, Arie J. Pitono / Jurnal Analis Kesehatan Klinikal Sains 9 (2) (2021)

\begin{tabular}{|c|c|c|c|c|c|c|c|}
\hline No & $\begin{array}{c}\text { Kode } \\
\text { Samp } \\
\text { el }\end{array}$ & $\begin{array}{l}\text { Bagian } \\
\text { Sampel }\end{array}$ & $\begin{array}{c}\text { As.flavu } \\
\text { s }\end{array}$ & $\begin{array}{c}\text { As.fumigatu } \\
s\end{array}$ & As.niger & $\begin{array}{c}\text { As.terreu } \\
\text { s }\end{array}$ & Keterangan \\
\hline \multirow[t]{4}{*}{1.} & RT 1 & Atas & - & + & - & - & As. \\
\hline & & & & & & & fumigatus \\
\hline & & $\begin{array}{l}\text { Tenga } \\
\mathrm{n}\end{array}$ & - & - & - & - & - \\
\hline & & Bawah & - & - & - & - & - \\
\hline \multirow[t]{3}{*}{2.} & RT 2 & Atas & - & - & - & - & - \\
\hline & & $\begin{array}{l}\text { Tenga } \\
\mathrm{n}\end{array}$ & - & - & - & - & - \\
\hline & & Bawah & - & - & - & - & - \\
\hline \multirow[t]{3}{*}{3.} & RT 3 & Atas & - & + & - & - & $\begin{array}{c}\text { As. } \\
\text { fumigatus }\end{array}$ \\
\hline & & $\begin{array}{l}\text { Tenga } \\
\mathrm{h}\end{array}$ & - & - & - & - & - \\
\hline & & Bawah & - & + & - & - & $\begin{array}{c}\text { As. } \\
\text { fumigatus }\end{array}$ \\
\hline \multirow[t]{3}{*}{4.} & RT 4 & Atas & - & - & - & - & - \\
\hline & & $\begin{array}{l}\text { Tenga } \\
\mathrm{h}\end{array}$ & - & - & - & - & - \\
\hline & & Bawah & + & - & - & - & As. flavus \\
\hline
\end{tabular}

Pada tabel 3 menunjukan data hasil pengamatan secara makroskopik dan mikroskopik ditemukannya 2 jenis jamur kontaminan pada roti tawar 2 hari sebelum masa kadaluarsa di Pasar Burungtungku Kota Bandung yaitu Aspergillus flavus dan Aspergillus fumigatus.

Penelitian dilakukan untuk mengidentifikasi jamur Aspergillus sp pada roti tawar 2 hari sebelum masa kadaluarsa di Pasar Burung Tungku Kota Bandung. Dari penelitian dilakukan dengan mengambil sampel roti tawar sebanyak 4 jenis roti tawar yang di jual oleh 2 pedagang di Pasar Burung Tungku Kota Bandung. Penelitian dilakukan sesuai dengan kriteria peneliti yaitu sampel di periksa 2 hari sebelum masa kadaluarsa. Penelitian ini dilakukan di Laboratorium Bakteriologi dan Parasitologi Institut Kesehatan Rajawali Bandung.

Penelitian dimulai dengan pengumpulan sampel yang dilakukan dengan memilih 4 jenis roti tawar di Pasar Minggu Burung Tungku Kota Bandung. Kemudian memberikan kode sampel pada masing-masing roti, setelah itu sampel roti diisolasi pada media SDA selama 5 hari pada inkubator dengan suhu $27^{\circ} \mathrm{C}$. Setelah diisolasi selama 5 hari selanjutnya dilakukan pengamatan secara makroskopik untuk mengidentifikasi ada atau tidaknya pertumbuhan jamur Aspergillus pada media SDA (Mizana et al., 2016).

Untuk mengidentifikasi jamur apa yang tumbuh pda media SDA maka dilakukan identifikasi secara makroskopik. Dimana pengamatan secara makroskopik ini dilihat dari warna 
koloni jamur, radial furrow, exudate drop, warna atas dan warna pinggiran. Dimana dari hasil pengamatan tersebut di sesuaikan dengan cir-ciri makroskopik dari jamur Aspergillus. Setelah selesai pengamatan secara makroskopik dilakukan pengamatan secara mikroskopik. Pada pengamatan secara makroskopik masing-masing sampel yang di tumbuhi jamur di ambil koloninya, kemudian letakan koloni di atas objek glass bersih yang sudah diberi satu tetes larutan Lactophenol Catton Blue (LPCB) kemudian tutup dengan cover glass Amati di bwah mikroskop dengan perbesaran 10-40x dengan melihat adanya jamur serta dilihat dari warna jamur, bentuk, konidia, vesicle dan hifa (Praja et al., 2017).

Pada penelitian ini, dari 4 jenis roti tawar, 3 jenis sampel roti tawar 2 hari sebelum masa kadaluarsa hasilnya positif ditemukannya jamur kontaminan, dari 3 jenis sampel diantaranya adalah sampel roti tawar 1 , roti tawar 3, dan roti tawar 4 . Berdasarkan hasil pengamatan secara makroskopik dan mikroskopik jamur kontaminan pada sampel roti tawar 1 dan 3 merupakan jenis jamur Aspergillus fumigatus, dan sampel roti tawar 4 merupakan jenis jamur Aspergillus flavus. Penelitian ini sejalan dengan penelitian (Syaifudin 2017), berdasarkan data hasil penelitian roti tawar yang memiliki masa kadaluarsa dua hari sebelum masa kadaluarsa ditemukan jamur Aspergillus flavus, Aspergillus niger dan Aspergillus fumigatus. Roti tawar tepat saat kadaluarsa sesuai tanggal pada kemasaan ditemukan jamur Aspergillus flavus dan Aspergillus niger. Sedangkan roti tawar dua hari setelah tanggal kadaluarsa ditumbuhi jamur Aspergillus flavus dan Aspergillus niger. Berikut ini hasil pewarnaan Aspergilus flavus dapat dilihat pada gambar 1.

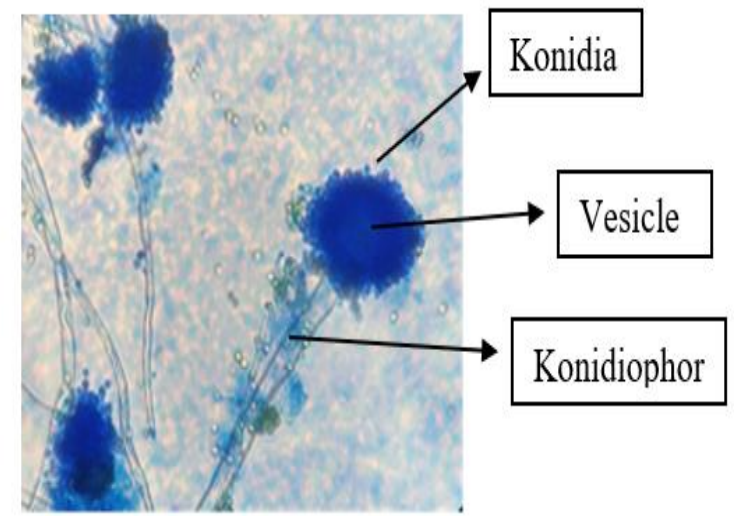

Gambar 1. Jamur Aspergillus flavus

Jamur Aspergillus flavus merupakan jamur kontaminan pada makanan yang sering mengkontaminasi makanan salah satunya adalah roti tawar. Aspergillus flavus menghasilkan racun yang disebut aflatoksin (Aspergillus flavustoksin). Aspergillus flavus sebagai penghasil utama aflatoksin umumnya hanya memproduksi aflatoksin B1, dan B2 (AFB1 dan AFB2), 
aflatoksin B1 penyebab keracunan, selain itu aflatoksin dapat menyebabkan penyakit kanker hati.

Jamur Aspergillus fumigatus merupakan jamur kontaminan pada makanan yang dapat di temukan pada sayuran busuk, sampah daun atau kompos, serta makanan berbahan dasar dari tepung terigu salah satunya roti. Jamur Aspergillus flavus merupakan penyebab aspergillosis pada manusia dan juga hewan. Koloni Aspergillus fumigatus berwarna hijau kelabu atau hijau tua dengan pinggiran berwarna putih, permukaan koloni seperti buludru (Gandi et al., 2019). Ditemukannya jamur Aspergillus sp pada sampel roti tawar 2 hari sebelum masa kadaluarsa dapat diakibatkan oleh beberapa faktor misalnya dari bahan pembuatan roti tawar yang tidak sesuai, cara pengemasan, pencahayaan juga dapat mempengaruhi tumbuhnya jamur, serta faktor lingkungan bisa saja dari suhu ataupun udara karena udara atau debu yang menempel pada makanan dapat mempengaruhi pertumbuhan jamur pada makanan sehingga makanan rentan terkontaminasi. Selain dari faktor lingkungan bisa saja dari komponen media seperti nutrisi yang terdapat pada media SDA karena jamur dapat tumbuh pada media yang kaya akan nutrisi yang dibutuhkan oleh jamur. Oleh sebab itu sebelum membeli atau mengkonsusmsi roti tawar, selain memperhatikan tanggal kadaluarsa perhatikan juga kondisi fisik roti tawar tersebut, seperti warna roti, rasa dan bau, serta dilihat dari pengemasan karena dengan pengemasan yang baik dapat melindungi roti dari air dan debu yang masuk pada roti. Roti tawar yang layak konsumsi memiliki bentuk ideal, memiliki warna putih bersih, memiliki tekstur yang lembut, serta tidak berbau. Sebaiknya membeli roti tawar dengan tanggal kadaluarsa yang masih baru untuk meminimalisir adanya jamur pada roti tersebut. Menurut penelitian Mizana (2016) bagi masyarakat supaya tidak mengkonsumsi roti tawar

\section{SIMPULAN}

Berdasarkan hasil peneliian yang diperoleh maka dapat disimpulkan sebagai berikut:

Ditemukannya jamur Aspergillus fumigatus pada roti tawar 2 hari sebelum masa kadaluarsa pada sampel roti tawar 1 dan 3 , jamur $A$ spergillus flavus pada sampel roti tawar 4 yang di jual di Pasar Minggu Burung Tungku. Diperoleh gambaran makroskopik dan mikroskopik jamur Aspergillus, koloni berwarna hijau dengan adanya tangkai konidia (hifa) bening tidak bersepta, vesicel dan konidia berbentuk bulat berwarna biru, pada roti tawar sebelum masa kadaluarsa di Pasar Minggu Burung Tungku Kota Bandung.

\section{UCAPAN TERIMA KASIH}


Ni’matul Murtafi'ah, Nurhani Sapitri, Arie J. Pitono / Jurnal Analis Kesehatan Klinikal Sains 9 (2) (2021)

Saya ucapkan terimakasih kepada LPPM Institut Kesehatan Rajawali Bandung yang telah memotivasi dalam penelitian ini. Ketua Laboratorium telah memberikan izin untuk melakukan penelitian. Terimakasih ditujukan kepada semua rekan yang terlibat dalam membantu menyelesaikan penelitian ini.

\section{DAFTAR PUSTAKA}

[1] Gandi, NLPG \& Getas, IW 2019, 'Jannah M. Studi jamur Aspergillus fumigatus penyebab aspergilosis di Pasar Cakranegara Kota Mataram dengan media pertumbuhan Potato Dextrose Agar (PDA)', Jurnal AMBS, vol. 6, no. 1.

[2] Hasanah, U 2017, 'Mengenal aspergilosis, infeksi jamur genus Aspergillus', Jurnal $K S S$, vol. 15 , no .2, hh. 76-86.

[3] Mizana, DK, Suharti, N \& Amir, A 2016, 'Identifikasi pertumbuhan jamur Aspergillus sp pada roti tawar yang dijual di Kota Padang berdasarkan suhu dan lama penyimpanan', Jurnal KA, vol. 5, no. 2, hh. 355-60.

[4] Praja, RN \& Aditya, Y 2017, 'Isolasi dan identifikasi Aspergillus sp pada paru-paru ayam kampung yang dijual di Pasar Banyuwangi', Jurnal MV, vol. 1, no. 1, hh. 6-11.

[5] Prasetyarini, FD, Mustadjab, MM \& Hanani, N 2014, 'Analisis penyediaan pangan untuk meningkatkan ketahanan pangan di Kabupaten Sidoarjo', Jurnal AGRES, vol. 14, no. 3, hh. 206-17.

[6] Pusuma, DA, Praptiningsih, Y \& Choiron, M 2018, 'Karakteristik roti tawar kaya serat yang disubstitusi menggunakan tepung ampas kelapa', Jurnal Agroteknologi, vol. 18 , no. 1 , hh. $29-42$.

[7] Sari, NM \& Wantini, S 2017, 'Gambaran jamur Aspergillus flavus pada kecap manis hasil industri rumahan yang dijual di Pasar Kipondo dan Pasar Margorejo Kota Metro', Jurnal AK, vol.6, no. 1, hh. 585-9.

[8] Sugiyono, 2016, Metode penelitian kuantitatif, kualitatif dan R\&D, Bandung, Alfabeta.

[9] Sulastina, NA 2020, 'Analisis jamur kontaminan pada roti tawar yang dijual di Pasar Tradisional', Jurnal SM, vol. 5, no. 1, hh. 122-30.

[10] Syaifuddin, AN 2017, 'Identifikasi jamur Aspergillus sp pada roti tawar berdasarkan masa sebelum dan sesudah kadaluarsa', KTI. Jombang, Stikes Insan Cendikia Medika Jombang. 